\title{
Focus on analytical chemistry to illuminate the past
}

\author{
Maria Perla Colombini
}

Published online: 6 August 2011

(C) Springer-Verlag 2011

Analytical chemistry has particularly significant importance in describing the composition of materials used or manipulated in the past. More widely, it is a fundamental part of archaeometry, a word coined in 1955 by Christopher Hawkes (he was Professor of European Archaeology at Oxford University) which originated from archaeology. Today it comprises all the scientific disciplines, technology, and methods used for extrapolating information from archaeological findings and contexts, and precious and artistic heritage objects. Archaeometry is thus the scientific study of the materials that make up objects, of organic and inorganic residues inside objects, and of the environments surrounding such objects.

For such purposes and to establish the state of conservation, historians, archaeologists and art experts no longer look only at the visual appearance, the quality of patina, the weight and shape of ceramic pots, etc. They require sound scientific investigations as a means for acquiring information on the materials that make up the object and also for assessing decay. With this new knowledge restoration approaches can be planned and historical interpretation can be made.

Consequently, over the last few years multi-disciplinary collaborations have flourished among researchers in archaeological sites, museums, conservation institutions, universities and scientific laboratories. To tackle any environmental or material problem safely and efficiently, reliable analytical

Published in the special issue Analytical Chemistry to Illuminate the Past with guest editor Maria Perla Colombini.

M. P. Colombini $(\square)$

Dipartimento di Chimica e Chimica Industriale, Università di Pisa, via Risorgimento 35,

56126 Pisa, Italy

e-mail: perla@dcci.unipi.it methods are needed, with analysts working in interdisciplinary teams with archaeologists, biologists, pharmacists, and historians.

Progress in analytical chemistry for archaeometry would especially benefit applications with diverse approaches and methods, and, above all, the continuous exchange of ideas. The reliability of analytical procedures adopted should be demonstrated by using certified reference materials. Because, in this field, they do not exist, laboratories should exploit round-robin exercises to demonstrate their expertise.

Recent developments in analytical methods and procedures that are able to use very minute samples (a few micrograms), together with the increased availability of advanced analytical instrumentation, have led to great interest in the chemical study of materials found in archaeological or historical vessels related to various aspects of everyday life in past societies.

There has been a particular focus on the characterization of organic materials occurring, for example, as the residues of food, cosmetics, medicines, and balms in archaeological potteries and mummies, of adhesives and waterproofing materials in shipwrecks, and of colorants in textiles and funerary practices.

The chemical study of these materials rapidly provides a picture of the technology, social customs, diet, and rituals, in the context in which they were used. Their characterisation, if interpreted together with the information derived from the critical study of historical documents and of "in-situ evidence", reveals the preparation, conservation, and uses of the substances investigated.

Although it is certainly exciting to reveal the secrets of the past and to develop the long-term preservation of materials, the difficulties involved in characterising "cultural heritage samples" must still be born in mind. The very small size of samples, the mixtures of many materials, and the 
chemical changes caused by ageing and human intervention all make it even more difficult to study these samples and are a challenge for analytical chemists.

In this respect, research relies heavily on structural information at a molecular level, and thus the application of mass spectrometry (MS) plays a prominent role. The coupling of mass spectrometry with gas chromatography (GC) and high-performance liquid chromatography (HPLC) make MS the most powerful tool for investigation of the complex and aged mixtures of organic molecules encountered as constituents of historic and archaeological objects. Nevertheless, direct mass spectrometric techniques, for example direct exposure mass spectrometry (DE-MS), laser desorption mass spectrometry (LDMS), and ESI-MS may successfully be used for rapid recognition of, for instance, resinous materials, lipids, and colorants.

Molecular spectroscopic techniques, i.e. infrared, Raman, and fluorescence spectroscopy, also play an important role in classifying materials and assessing the state of oxidation. NMR techniques are less frequently used but, because of improved instrumentation, there is increasing interest in archaeometric applications. The application of synchrotron micro-analytical based techniques, which exploit the high photon flux and coherence of synchrotron radiation, has also found increasing success in the field of cultural heritage.

The advent of such advanced analytical instrumentations and improved analytical procedures has enabled the growth of research and has catalysed interest in archaeometry. So, while practical analysis has been extended to organics of increasing complexity-proteinaceous materials, vegetable resins, lipids, waxes, fossil resins, gums, vegetable and animal colorants - the degradation patterns have resulted in further insight into the relationships between organic material, object, and environment.

The application of these analytical tools to a large series of case studies has shown how chemical investigation of the residues of medicines and make-up materials that are found in stone, ceramic, or glass containers in archaeological or historical sites is an extraordinary source of information about how they were made and, more generally, about chemical and pharmaceutical knowledge and practices in antiquity.

For example, studies of the funerary objects, including toiletry tools and make-up receptacles, sometimes found in an exceptionally good state of conservation in Egyptian tombs have confirmed that cosmetics and make up were used not only for aesthetic purposes, but also for religious or healing reasons: they were, in fact, important during rituals and burial ceremonies, and in some cases had real therapeutic results.

As another example, tracing the routes over which olive oil and wine were transported by amphorae is of great interest: is it possible to find scientific criteria which enable us to establish, with certainty, and without taking into account the shape, that one given amphora contained a specific commodity? Contradictory answers are reported in the literature: the detection of stable molecular markers, e.g. tartaric acid for wine and fatty acid pattern for olive oil, is fairly difficult and often not sufficiently reliable to assess the presence of these materials. Thus, although some questions in archaeometry have been answered, others remain open.

Several papers and case studies on the characterization of amorphous materials in ancient objects have recently appeared in specialized journals and congresses; with a few exceptions, however, such information is difficult to access, because of its specialized and fragmentary nature. This special issue provides an overview of the state of the art in the field and describes an important field within archaeological science, thus making an important contribution to the discipline as a whole.

It attempts to reach conclusions, highlight achievements, identify gaps, and discuss recent research and new developments in the chemical study of archaeological-historical herbal, pharmaceutical, cosmetic, and ritual preparations.

By shedding light on the past, analytical chemistry provides vital information for successfully approaching the future.

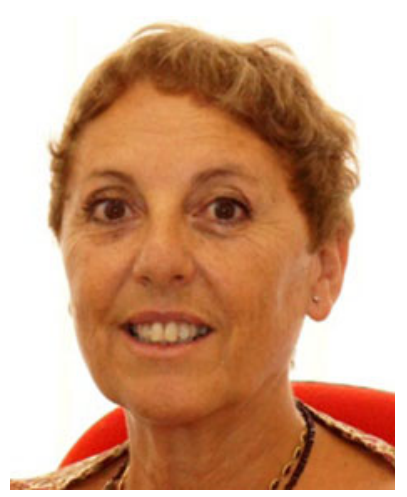

Maria Perla Colombini

is currently Full Professor of Analytical Chemistry at the Department of Chemistry, Faculty of Natural, Mathematical and Physical Sciences of the University of Pisa. Her research focuses on the development of analytical procedures based on mass spectrometric and chromatographic techniques for characterisation of natural and synthetic organic materials (e.g. proteinaceous binders, siccative oils, vegetable resins, colorants, gums) and their degradation products in works of art and archaeological objects. Her research has resulted in over 160 publications in refereed journals and she is the editor of three books. She is head of a Master's in "Material and diagnostic technique in cultural heritage" and is currently President of the Italian Archaeometry Association. 